\title{
Comportamento ingestivo, consumo de forragem e desempenho de cabritas alimentadas com diferentes níveis de suplementação
}

\author{
Paulo Fernando Adami (1), Christiano Santos Rocha Pitta ${ }^{(1)}$, André Luís Finkler da Silveira( ${ }^{(2)}$, Adelino Pelissari(1), \\ João Ari Gualberto Hill(2), Alceu Luiz Assmann ${ }^{(2)}$ e Jussara Maria Ferrazza(1)
}

(1)Universidade Federal do Paraná, Departamento de Agronomia, Rua dos Funcionários, oo 1.540, Caixa Postal 1.9061, CEP 80035-050 Curitiba-PR. E-mail: paulo.adami@ifpr.edu.br, christiano.pitta@ifpr.edu.br, linopeli@hotmail.com, jussaraferrazza@yahoo.com.br (2)Instituto Agronômico do Paraná, Rodovia BR 158, Km 5.517 SR, Caixa Postal 510, CEP 85501-970 Bom Retiro, Pato Branco, PR. E-mail: andrefinkler@iapar.br, joaohill@iapar.br, assmann@iapar.br

Resumo - O objetivo deste trabalho foi avaliar as alterações no comportamento ingestivo, consumo diário de forragem e desempenho de cabritas alimentadas com diferentes níveis de suplementação, em pastagem de aveia-preta (Avena strigosa, 'IAPAR 61'). Foram utilizadas 36 cabritas da raça Boer, com 10 meses de idade e peso médio inicial de $21 \mathrm{~kg}$, que receberam suplementação alimentar com milho moído e farelo de soja a $0,0,5$, 1 e 1,5\% do peso vivo, em pastejo de lotação contínua com taxa de lotação variável. Utilizou-se o delineamento experimental de blocos ao acaso com três repetições. Foram avaliados: altura, taxa de acúmulo, massa, oferta e estrutura da pastagem; carga animal; ganho de peso individual e por área; e tempo de pastejo, ruminação e ócio (comportamento ingestivo); além do consumo de forragem. A suplementação diminuiu o consumo de forragem - 2,4, 1,45, 1,43 e 1,05\% do peso vivo, nos tratamentos com $0,0,5,1$ e 1,5\%, respectivamente -, o tempo de pastejo diário e o ganho de peso individual. Os níveis de suplementação não alteraram o consumo total de matéria seca (forragem + concentrado) e nem o tempo de ruminação, mas aumentaram o tempo de ócio, o que permitiu maior desempenho dos animais por área.

Termos para indexação: estrutura da pastagem, ganho de peso, óxido de cromo, tempo de pastejo.

\section{Ingestive behavior, forage intake and performance of goats fed with different levels of supplementation}

\begin{abstract}
The objective of this work was to evaluate changes in ingestive behavior, dry matter intake, and performance of goats fed with different levels of supplementation, in black oat pasture (Avena strigosa, 'IAPAR $61 ')$. Thirty-six ten-month-old Boer goats were used, with an initial average weight of $21 \mathrm{~kg}$, which received supplementation with $0,0.5,1$ and $1.5 \%$ of body weight, in continuous stocking grazing with variable stocking rate. A randomized block design was used with three replicates. Evaluations were done for: height, accumulation rate, mass, offer, and structure of the pasture; stocking rate; individual and per-area weight gain; and time used for grazing, rumination and resting periods (ingestive behavior); besides forage intake. Supplementation decreased forage intake $-2.4,1.45,1.43$, and $1.05 \%$ of body weight, in treatments with $0,0.5,1$ and $1.5 \%$, respectively -, daily grazing time, and the individual weight gain. The supplementation levels did not change total dry matter intake (forage + concentrate) neither the rumination time, but they increased resting time, which allowed greater animal performance per area.
\end{abstract}

Index terms: pasture structure, live weight gain, chromium oxide, grazing time.

\section{Introdução}

O conhecimento das relações planta-animal é importante para uma eficiente utilização da pastagem. Segundo Jochims et al. (2010), estudos sobre os efeitos das condições de pastejo sobre o comportamento ingestivo, consumo de forragem e desempenho dos ruminantes são importantes para o manejo adequado do sistema de produção animal adotado.
Quando suplementos alimentares proporcionam maior aporte de nutrientes à dieta animal e, portanto, podem interferir no consumo de nutrientes e de forragem, essa interferência é comumente denominada de taxa de substituição ou efeito associativo (Bargo et al., 2003). Estes fatores, segundo Van Soest (1994) e Bargo et al. (2003), podem influenciar a carga e o desempenho animal (representado pelas distintas cargas animais impostas em razão das diferentes quantidades 
de suplementação), bem como o comportamento ingestivo (tempos de pastejo, ruminação e ócio) dos animais em pastejo (Gibb et al., 2002; Bargo et al., 2003; Gonçalves et al., 2009).

Sistemas de produção que usam apenas a pastagem como base alimentar podem apresentar desequilíbrio entre as exigências nutricionais e a quantidade de nutrientes fornecidos pela forragem, em virtude das oscilações climáticas e fenológicas da planta, o que pode reduzir o potencial produtivo e o lucro da atividade. Por outro lado, a falta de critérios no uso de suplementos pode aumentar os custos de produção sem que haja resposta produtiva, o que diminuiria o retorno da atividade.

A literatura é escassa quanto a sistemas de produção eficientes de caprinos (Simplício et al., 2004), principalmente em pastagens hibernais, associadas ao uso de suplementação alimentar.

O objetivo deste trabalho foi avaliar as alterações no comportamento ingestivo, consumo diário de forragem e desempenho de cabritas alimentadas com diferentes níveis de suplementação, em pastagem de aveia-preta (Avena strigosa, 'IAPAR 61').

\section{Material e Métodos}

O trabalho foi realizado na área experimental do Instituto Agronômico do Paraná (Iapar), Pato Branco, $\mathrm{PR}$, na região fisiográfica denominada Terceiro Planalto Paranaense, a $26^{\circ} 07^{\prime} \mathrm{S}$ e $52^{\circ} 39^{\prime} \mathrm{W}$ e a $700 \mathrm{~m}$ de altitude.

O clima da região é subtropical úmido, do tipo Cfa, conforme a classificação de Köppen (Maack, 1968). As condições meteorológicas registradas durante $\mathrm{o}$ período experimental e a média climatológica dos últimos 30 anos estão apresentadas na Figura 1.

O solo da área experimental é classificado como Latossolo Vermelho distroférrico, com textura argilosa (Santos et al., 2006).

Após a colheita da soja, foi aplicado glifosato na área, a $0,72 \mathrm{~kg} \mathrm{ha}^{-1}$ do equivalente ácido. Foram coletadas amostras de solo, com trado tipo holandês, na profundidade de $0-20 \mathrm{~cm}$, antes da semeadura de aveia-preta, para caracterização química da área.

A adubação química do solo foi realizada conforme recomendação de Oliveira (2003) e de acordo com os valores encontrados na análise de solo, que foram: $\mathrm{pH}-\mathrm{CaCl}_{2}, 5,0 ; \mathrm{P}, 9,06 \mathrm{mg} \mathrm{dm} \mathrm{dm}^{-3}$; $\mathrm{K}, 0,88 \mathrm{cmol}_{\mathrm{c}} \mathrm{dm}^{-3} ; \mathrm{MO}, 60,3 \mathrm{~g} \mathrm{~kg}^{-1}$; Ca, 7,28 $\mathrm{cmol}_{\mathrm{c}} \mathrm{dm}^{-3}$; $\mathrm{Mg}, 3,38 \mathrm{cmol}_{\mathrm{c}} \mathrm{dm}^{-3}$; Al, $0,00 \mathrm{cmol}_{\mathrm{c}} \mathrm{dm}^{-3}$ e $69,7 \%$ de saturação por bases. Foram aplicados $250 \mathrm{~kg} \mathrm{ha}^{-1}$ do adubo formulado 04-30-10 e $150 \mathrm{~kg} \mathrm{ha}^{-1}$ de $\mathrm{N}$, na forma de ureia, como adubação de cobertura no início do perfilhamento (25 dias após a emergência).

A aveia-preta cultivar IAPAR 61 foi semeada (300 sementes $\mathrm{m}^{-2}, 50 \mathrm{~kg} \mathrm{ha}^{-1}$ ) por semeadura direta, aos 15 dias após a dessecação (20/04/2010), em espaçamento entre linhas de $17 \mathrm{~cm}$. O delineamento experimental utilizado foi o de blocos ao acaso, com três repetições. Os tratamentos foram compostos por quatro níveis de suplementação - 0, 0,5, 1 e 1,5\% do peso vivo (PV) -, com uso do suplemento constituído por milho moído e farelo de soja, formulado com $16 \%$ de proteína bruta $(\mathrm{PB})$ e $82 \%$ de nutrientes digestíveis totais (NDT). Os quatro níveis de suplementação supriram em $0,19,38$ e $57 \%$ as exigências em consumo de energia, relativas ao ganho diário de $150 \mathrm{~g}$, conforme recomendação do National Research Council (2007), para a categoria.

Os animais foram pesados e alocados aleatoriamente nos tratamentos, aos 56 dias após a emergência da aveia-preta, após terem permanecido 12 dias de
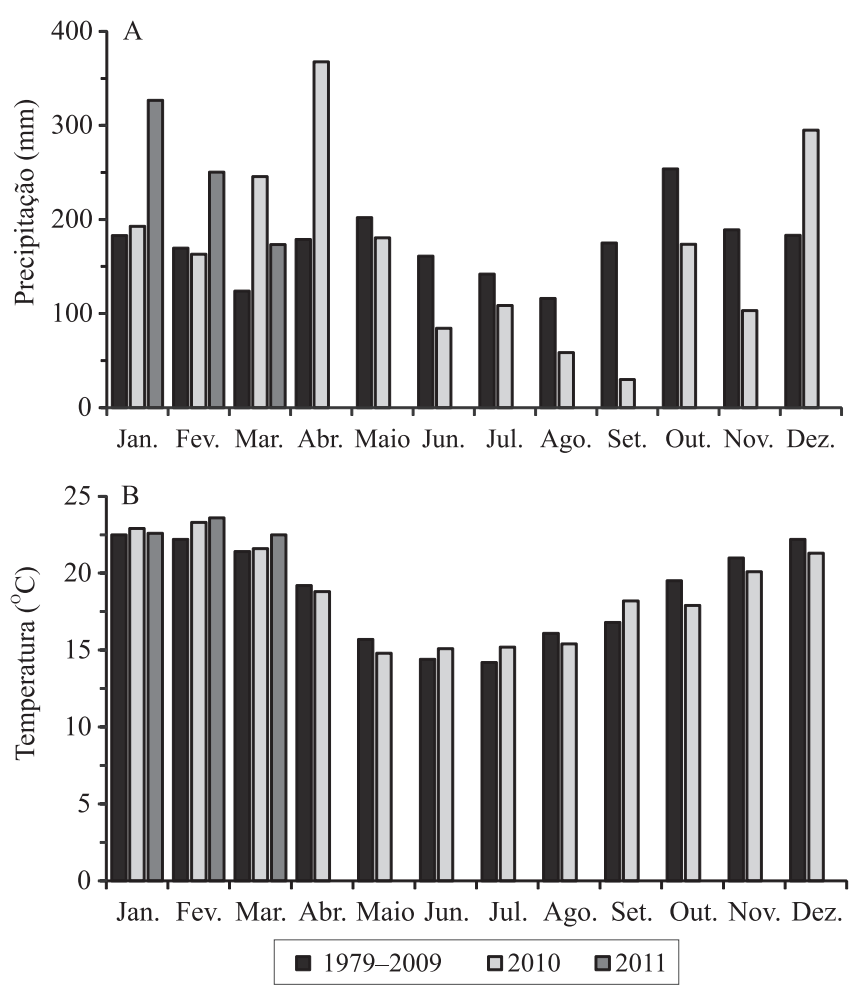

Figura 1. Dados meteorológicos históricos (média de 30 anos) e os observados durante o período experimental, na Estação Meteorológica do Instituto Agronômico do Paraná (Iapar), em Pato Branco, PR. 
período de adaptação, em pastagem da mesma espécie de aveia. As pesagens ocorreram após jejum de sólidos e líquidos por 14 horas, em intervalos aproximados de 21 dias, com cinco avaliações no período de pastejo. O controle de endoparasitas e ectoparasitas foi realizado no início do experimento e monitorado conforme o método Famacha (Van Wyk et al., 2004).

O término do experimento ocorreu em 31/08/2010, num total de 77 dias de experimentação, divididos em quatro períodos de 15, 21, 20 e 21 dias, com as respectivas datas de avaliação em 15/06, 30/06, 21/07, 10/08 e 31/08/2010.

Em razão das diferentes cargas animais esperadas para os diferentes níveis de suplementação, o tamanho dos piquetes foi de 950, 850, 700 e $600 \mathrm{~m}^{2}$ para suplementação com $0,0,5,1$ e 1,5\% do PV, respectivamente,. Os piquetes foram delimitados e divididos com cerca eletrificada e tela. Em todas as parcelas, utilizaram-se apriscos de $4 \mathrm{~m}^{2}$, compostos por cochos para fornecimento do suplemento e de sal mineralizado, fornecido sem restrição, e de um bebedouro automático para fornecimento de água. Neste sistema, o suplemento foi fornecido diariamente às $8: 30 \mathrm{~h}$ e às $15: 30 \mathrm{~h}$.

Cada parcela continha três animais caprinos da raça Boer, com idade média de 10 meses e com $21 \mathrm{~kg}$, no início do experimento, num total de 36 animais, que permaneceram fixos nos piquetes durante todo o período experimental. Utilizou-se o sistema de pastejo contínuo, com taxa de lotação variável (Mott \& Lucas, 1952), em que foram usados, como reguladores, animais da mesma idade, peso e categoria dos avaliados, pelo tempo necessário para manter a altura da pastagem entre 15-20 cm (Aguinaga et al., 2006). As avaliações de altura da pastagem foram realizadas semanalmente, com o auxílio de bastão graduado, com amostragem aleatória de 50 pontos por piquete, pelo método descrito por Hodgson (1990), a fim de regular a carga animal conforme a necessidade.

A massa de forragem (MF) foi avaliada nas mesmas datas das pesagens dos animais, por meio de cinco coletas de toda a biomassa acima do mantilho, com o auxílio de quadrado de ferro com área de $0,25 \mathrm{~m}^{2}$, tendo-se percorrido o piquete em zigue-zague. Após o corte, as amostras foram identificadas, pesadas e secas em estufa com circulação forçada de ar a $65^{\circ} \mathrm{C}$, até atingir massa constante; a massa de forragem foi calculada e expressa em massa de matéria seca
(MS, $\left.\mathrm{kg} \mathrm{ha}^{-1}\right)$. Com a soma de todas as avaliações, foi determinada a produção total de forragem.

A taxa de acúmulo diário de forragem (TAD, $\mathrm{kg} \mathrm{ha}^{-1}$ de MS por dia) foi determinada por meio de duas gaiolas de exclusão do pastejo, por unidade experimental. A oferta de forragem ( $\mathrm{kg}$ de MS por $100 \mathrm{~kg}$ de PV) foi calculada por meio da divisão da disponibilidade de forragem diária [(MF inicial + TAD) /número de dias)], entre as avaliações (15, 21, 20 e 21 dias), pela carga animal média do período (obtida do peso vivo dos animais, avaliados e reguladores).

Para a avaliação dos componentes estruturais da pastagem (lâmina foliar, colmo com bainha e material morto), duas amostras de $0,25 \mathrm{~m}^{2}$ foram colhidas por piquete, em cada data de avaliação. Os componentes foram separados manualmente, colocados em sacos de papel, identificados e levados à estufa com circulação forçada de ar a $65^{\circ} \mathrm{C}$, até atingirem massa constante, para determinação da participação de cada um deles na massa de forragem da pastagem. O percentual de cada componente foi multiplicado pela massa de forragem do mesmo período e piquete, para obtenção da massa de cada componente em MS ( $\left.\mathrm{kg} \mathrm{ha}^{-1}\right)$.

A carga animal (em kg ha-1 de PV por dia) foi obtida por meio da divisão da média ponderada do peso vivo dos animais reguladores, em cada período, pelo número de dias que cada um permaneceu no piquete, tendo-se acrescentado o peso médio dos animais avaliados.

Os ganhos médios diários (GMD, em kg por animal por dia) foram obtidos pela diferença entre o peso final e o peso inicial dos animais avaliados, em cada período, e o resultado foi dividido pelo número de dias transcorridos entre as pesagens.

O ganho de PV ( $\left.\mathrm{kg} \mathrm{ha}^{-1}\right)$, em cada período, foi obtido pela multiplicação do GMD dos animais avaliados pela taxa de lotação. O ganho total de peso vivo corresponde ao somatório das produções de cada período.

O consumo de forragem foi estimado pela relação entre a produção fecal (PF, g por dia) e a indigestibilidade da matéria seca (IDMS), em que o consumo de forragem (g por dia) é igual a PF/IDMS, em que: IDMS $=1-$ digestibilidade da MS. A estimativa da excreção fecal foi realizada mediante o uso de óxido de cromo $\left(\mathrm{Cr}_{2} \mathrm{O}_{3}\right)$ como marcador externo. Para isso, cápsulas com $0,5 \mathrm{~g}$ de $\mathrm{Cr}_{2} \mathrm{O}_{3}$ foram administradas duas vezes ao dia, por 12 dias consecutivos, imediatamente após os animais receberem o suplemento. Os resultados encontrados foram transformados em consumo de forragem por percentagem do PV. 
A produção fecal foi medida nos últimos cinco dias de fornecimento do indicador, e as amostras de fezes foram coletadas diretamente do reto dos animais, logo após o fornecimento das cápsulas. As amostras de fezes foram pesadas e imediatamente congeladas. Posteriormente, foram secas em estufa com circulação forçada de ar a $55^{\circ} \mathrm{C}$, por cinco dias, e trituradas em moinho tipo Wiley provido de peneira com malhas de $1 \mathrm{~mm}$. As amostras, por animal, foram homogeneizadas para constituírem amostras compostas.

O cromo nas fezes e no óxido de cromo foi determinado por espectrofotometria de absorção atômica, por meio do método de Willians et al. (1962).

A recuperação fecal do cromo foi medida pela relação entre a quantidade de indicador excretado e a quantidade ingerida. A produção fecal (PF) dos animais foi, então, calculada como PF (g por dia) = indicador administrado ( $\mathrm{g}$ por dia)/concentração do indicador nas fezes $\left(\mathrm{g} \mathrm{kg}^{-1}\right.$ de MS).

Para a determinação dos resíduos indigestíveis, $0,5 \mathrm{~g}$ de cada amostra dos alimentos e das fezes foram pesados em duplicata, em sacos de TNT $\left(100 \mathrm{~g} \mathrm{~m}^{-2}\right)$ de $5 \times 5 \mathrm{~cm}$, selados e incubados no rúmen de dois caprinos Boer fistulados (aproximadamente $60 \mathrm{~kg}$ de PV), mantidos em baias separadas com feno de aveia e suplementação diária de $0,5 \mathrm{~kg}$ do suplemento utilizado nos outros animais. Os sacos foram removidos do rúmen após 240 horas de incubação, lavados intensivamente em água corrente, secos em estufa com ventilação forçada a $65^{\circ} \mathrm{C}$ por 24 horas e, em seguida, em estufa não ventilada por $105^{\circ} \mathrm{C}$, durante uma hora, e pesados. A matéria seca residual foi considerada indigestível (MSi).

Foram realizadas duas avaliações de comportamento ingestivo, nos dias 26/06 e 20/08/2010, ambas durante o período de 24 horas, com o método descrito por Jamieson \& Hodgson (1979). Os tempos de pastejo, ócio e ruminação nos animais avaliados foram observados a intervalos de $10 \mathrm{~min}$. O tempo gasto pelo animal na seleção e apreensão da forragem, inclusive os curtos espaços de tempo utilizados no deslocamento para seleção da forragem, foi considerado tempo de pastejo (TP). O tempo de ócio (TO) correspondeu ao período de descanso e outras atividades sem ser pastejo e ruminação. O tempo de ruminação (TR) correspondeu ao período de mastigação, exceto o período de colheita de forragem.

Os resultados foram analisados pelo programa computacional Statistical Analysis System, com uso do procedimento Mixed. O período experimental foi considerado medida repetida, com uso da opção "repeated". Quando a interação suplemento x período não foi significativa, optou-se por utilizar as médias do experimento avaliadas por regressão. Em caso de interação significativa entre suplemento $\mathrm{x}$ período, foram feitas as comparações de inclinação das retas dentro de cada período, por meio do procedimento GLM, conforme descrito por Kaps \& Lamberson (2004).

\section{Resultados e Discussão}

A suplementação das dietas produziu efeito significativo $(\mathrm{p}<0,0001)$ quanto à oferta de forragem, que apresentou média de $8,3 \mathrm{~kg}$ de MS por $100 \mathrm{~kg}$ de PV. Para cada $1 \%$ do nível de suplemento fornecido, ocorreu diminuição de $2,24 \mathrm{~kg}$ de MS por $100 \mathrm{~kg}$ de PV na oferta $\left(Y=9,9850-2,2425 x ; R^{2}=0,43\right.$ e $\mathrm{CV}=18,87 \%$ ). Esta redução, possivelmente, resultou do aumento da carga animal na área, propiciado pela inclusão do suplemento (Tabela 1).

Nas demais variáveis de pasto analisadas (Tabela 2), as oscilações observadas referem-se ao desenvolvimento da aveia, e são consideradas normais, por estarem relacionadas às alterações fenológicas da planta. A oscilação nos valores das variáveis avaliadas, no entanto, não foram suficientes para causarem condições de avaliação distintas entre os tratamentos ( $p>0,05)$, não causaram limitação ao consumo animal e estão em sintonia com o relatado na literatura (Gibb et al., 2002; Frescura et al., 2005; Assmann et al., 2010; Pellegrini et al., 2010).

O nível de suplementação teve efeito sobre os componentes do comportamento ingestivo - tempos de pastejo, ócio e ingestão do suplemento -, que se ajustaram ao modelo linear de regressão. Os animais

Tabela 1. Carga animal ( $\mathrm{kg} \mathrm{ha} \mathrm{h}^{-1}$ de peso vivo, PV) em função dos períodos de avaliação de cabritas em recria, suplementadas com $0,0,5,1$ e $1,5 \%$ do $\mathrm{PV}$, em pastagem de aveia-preta.

\begin{tabular}{|c|c|c|c|c|c|c|c|}
\hline \multirow[t]{2}{*}{ Período } & \multicolumn{4}{|c|}{ Nível de suplementação } & \multirow[t]{2}{*}{ Intercepto } & \multirow[t]{2}{*}{$\beta^{(1)}$} & \multirow[t]{2}{*}{$\mathrm{R}^{2}$} \\
\hline & 0 & 0,5 & 1 & 1,5 & & & \\
\hline $15 / 6$ a $30 / 6$ & 1.084 & 1.147 & 1.379 & 1.397 & 1.076 & $234 d$ & 0,50 \\
\hline $1 / 7$ a $21 / 7$ & 909 & 1.169 & 1.392 & 1.487 & 946 & $392 \mathrm{c}$ & 0,63 \\
\hline $22 / 7$ a $10 / 8$ & 941 & 1.043 & 1.207 & 1.636 & 870 & $450 \mathrm{~b}$ & 0,66 \\
\hline $11 / 8$ a $31 / 8$ & 1.039 & 1.161 & 1.158 & 1.897 & 928 & $514 \mathrm{a}$ & 0,62 \\
\hline Média & 987 & 1.130 & 1.277 & 1.620 & & & \\
\hline
\end{tabular}

${ }^{(1)}$ Valores de $\beta$ seguidos por letras iguais não diferem pelo teste $\mathrm{F}$, a $5 \%$ de probabilidade. 
mantidos sem suplementação apresentaram tempo de pastejo superior em 14,28 e $42 \%$ ao dos animais que receberam $0,5,1$ e $1,5 \%$ do PV de suplemento, respectivamente, o que corresponde a 52, 103 e 155 minutos a mais de pastejo por dia (Figura $2 \mathrm{~A}$ ).

Quanto às atividades de ócio, os valores encontrados para os tratamentos foram de 775, 817, 859 e $900 \mathrm{~min}$ (Figura 2 B). O tempo de ócio foi 84 min superior para cada $1 \%$ de suplemento fornecido, ou seja, os animais que não receberam suplementação permaneceram 5,4, 11 e $16 \%$ menos tempo em ócio, em comparação aos animais que receberam a suplementação de $0,5,1 \mathrm{e}$ $1,5 \%$ do $\mathrm{PV}$, respectivamente.

O tempo médio de ingestão de suplemento (IS) aumentou linearmente em função da suplementação, em 26, 45 e 63 min nos tratamentos de $0,5,1$ e 1,5\% do PV de suplemento (IS = 7,56 + 37,33x; $\mathrm{R}^{2}=0,7429$; $\mathrm{CV}=37,82 \%$ e $\mathrm{p}=0,0003)$, o que indica ter havido substituição do tempo destinado ao pastejo pelo tempo destinado ao consumo de suplemento e ao ócio.

O tempo de ruminação não foi afetado pelos períodos de avaliação e níveis de suplementação. Esse tempo corresponde ao valor médio de 280 minutos diários. Esperava-se que o suplemento tivesse efeito negativo na taxa de degradação ruminal, o que aumentaria o tempo de ruminação por grama de FDN no rúmen, o que, no entanto, não ocorreu. $\mathrm{O}$ consumo total (forragem + suplemento) dos animais apresentou médias diárias de $655,526,615$ e 676 g de MS, nos tratamentos com $0,0,5,1$ e $1,5 \%$ de suplementação do $\mathrm{PV}$, o que equivale a 2,4, 1,9, 2,4 e 2,5\% do PV.

Constatou-se que para cada $1 \%$ do PV fornecido de suplemento, houve redução de $0,85 \%$ do PV no consumo de forragem (Figura 3). Os animais suplementados com $0,5,1$ e $1,5 \%$ do PV apresentaram consumo de forragem em 39, 44 e 56\% menor, em comparação aos animais mantidos exclusivamente em pasto, o que caracteriza efeito de substituição da dieta, semelhantemente ao relatado por outros autores (Gibb et al., 2002; Bargo et al., 2003). De acordo com esses autores, à medida que se eleva o nível de suplementação e se reduz o tempo de pastejo, a taxa de ingestão permanece inalterada; assim, pode-se dizer que a demanda por nutrientes tem grande prioridade na regulação do tempo de pastejo. Cosgrove \& Edwards (2007) salientam, ainda, que, quando suplementos são fornecidos a ruminantes em pastejo, a taxa de ingestão permanece a mesma e, portanto, o consumo de matéria seca de forragem por unidade de tempo permanece constante e o tempo de pastejo diminui, na maior parte das vezes.

As diferenças na dieta, em razão da quantidade de suplemento fornecido, influenciaram os índices de desempenho animal. Os ganhos médios diários (GMD) (Figura 4) dos animais suplementados foram inferiores aos dos não suplementados. Contudo, este resultado foi compensado pelo ganho de peso por área (GPA). Além da influência da suplementação no comportamento ingestivo, a explicação para o menor GMD dos animais suplementados está no potencial de resposta à suplementação que, na maioria das vezes, depende do deficit energético dos animais criados apenas em pasto (Clark \& Woodward, 2007). Em pastagens de clima temperado, com elevados teores nutritivos, como a aveia, há tendência de ocorrerem menores ganhos individuais com a suplementação, pois, segundo Clark \& Woodward (2007), as respostas aos níveis de suplementação tendem a diminuir com o aumento no ganho de peso dos animais não suplementados, uma vez que estes se aproximariam de seu potencial produtivo. Resultados semelhantes foram encontrados por Ahuya et al. (2009), em sistemas de manejo semi-intensivo, com caprinos em pastagens estivais; entretanto, não foi encontrado, na literatura, trabalhos com caprinos suplementados em pastagens hibernais.

Tabela 2. Altura, massa de matéria seca de forragem, taxa de acúmulo diário de forragem, massa de lâminas foliares, massa de colmo e de material morto de aveia-preta pastejada por cabritas em recria (média dos quatro níveis de suplementação) ${ }^{(1)}$.

\begin{tabular}{|c|c|c|c|c|c|c|c|}
\hline \multirow[t]{2}{*}{ Parâmetro } & \multicolumn{5}{|c|}{ Data de avaliação } & \multirow[t]{2}{*}{ Média } & \multirow{2}{*}{$\begin{array}{l}\text { CV } \\
(\%)\end{array}$} \\
\hline & $15 / 6$ & $30 / 6$ & $21 / 7$ & $10 / 8$ & $31 / 8$ & & \\
\hline Altura $(\mathrm{cm})$ & $21,02 \mathrm{a}$ & $20,20 a$ & $18,19 b$ & $17,69 b$ & $14,71 \mathrm{c}$ & $18,36 \pm 0,23$ & 4,12 \\
\hline Matéria seca de forragem $\left(\mathrm{kg} \mathrm{ha}^{-1}\right)$ & $1.089 \mathrm{c}$ & $1.321 \mathrm{~b}$ & $1.094 \mathrm{c}$ & $1.258 \mathrm{~b}$ & $1.532 \mathrm{a}$ & $1.259 \pm 43,20$ & 10,70 \\
\hline Taxa de acúmulo ( $\mathrm{kg} \mathrm{ha}^{-1}$ por dia) & $42 \mathrm{ab}$ & $39 \mathrm{ab}$ & $32 \mathrm{bc}$ & $46 a$ & $25 c$ & $36,56 \pm 2,59$ & 24,31 \\
\hline Lâminas foliares $\left(\mathrm{kg} \mathrm{ha}^{-1}\right)$ & $744 \mathrm{ab}$ & $835 \mathrm{a}$ & $520 \mathrm{c}$ & $544 \mathrm{c}$ & $647 \mathrm{bc}$ & $658 \pm 35,17$ & 18,06 \\
\hline Colmo $\left(\mathrm{kg} \mathrm{ha}^{-1}\right)$ & $344 b$ & $351 b$ & $433 a b$ & $358 b$ & $540 \mathrm{a}$ & $405 \pm 37,93$ & 32,83 \\
\hline Material morto $\left(\mathrm{kg} \mathrm{ha}^{-1}\right)$ & Od & $134 \mathrm{c}$ & $141 \mathrm{c}$ & $247 b$ & $343 a$ & $173 \pm 26,52$ & 45,38 \\
\hline
\end{tabular}

${ }^{(1)}$ Médias seguidas por letras iguais não diferem pelo teste Tukey, a 5\% de probabilidade. 
A conversão alimentar dos animais mantidos a pasto, sem suplementação, foi menor $(5,1 \mathrm{~kg}$ de MS para $1 \mathrm{~kg}$ de PV) do que a observada nos animais que receberam a suplementação $(5,6,7,2$ e 7,3 kg de MS para $1 \mathrm{~kg}$ de $\mathrm{PV}$, nos tratamentos com suplementação de $0,5,1$ e $1,5 \%$ do $\mathrm{PV}$, respectivamente). $\mathrm{O}$ aumento na conversão alimentar possivelmente foi causado pela redução no $\mathrm{pH}$ ruminal em razão da inclusão do suplemento, o que teria reduzido a digestão de pasto. De forma complementar ao exposto por Clark \& Woodward (2007), esta possibilidade explicaria o menor desempenho individual com a inclusão do suplemento. Entretanto, à medida que se elevou a substituição da forragem pelo suplemento, aumentouse a carga animal comportada nas áreas de pastagem, o que promoveu incremento no ganho de peso por área (GPA) e caracterizou a ocorrência de efeito aditivo promovido pelo suplemento.

Os GMD e GPA apresentaram comportamento quadrático (Figura 4), em consequência dos tratamentos. O ponto de mínima eficiência com uso do suplemento foi de $0,44 \%$ do PV, para o GPA, e de $1,03 \%$ do PV, para o GMD. Valores acima dos mencionados
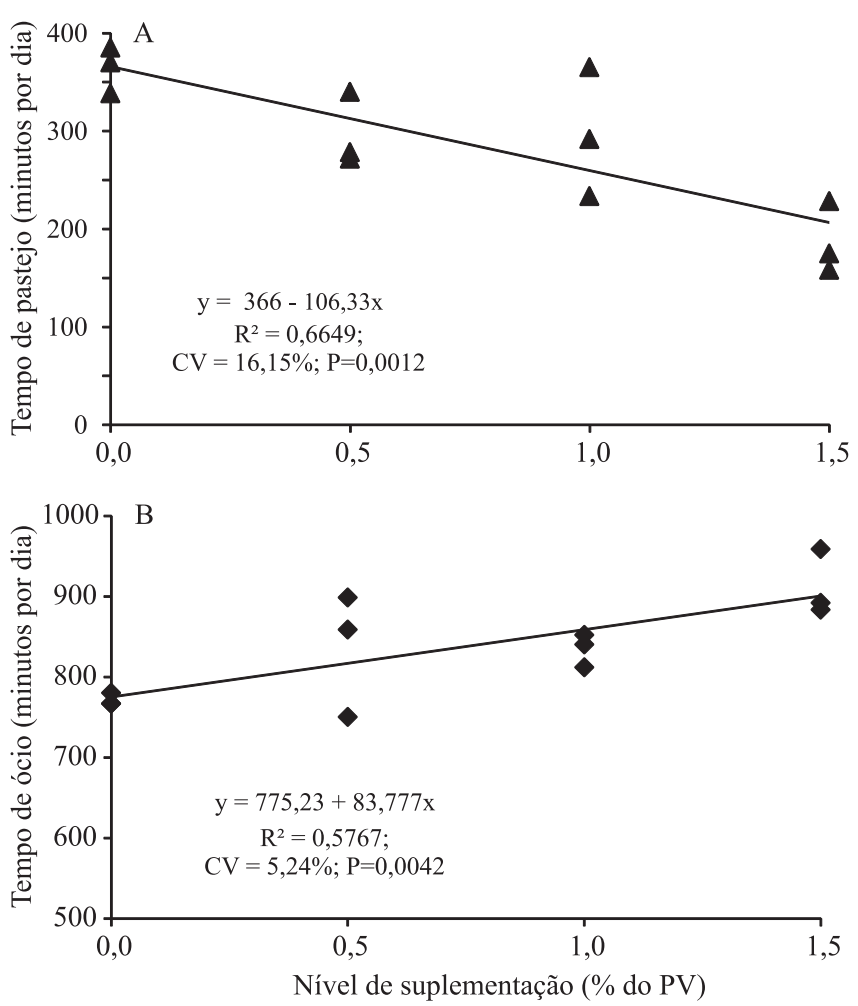

Figura 2. Tempo (minutos por dia) de pastejo e de ócio, de cabritas em recria, suplementadas com $0,0,5,1$ e $1,5 \%$ do peso vivo (PV), em pastagem de aveia-preta. proporcionam incremento do desempenho animal para as respectivas variáveis.

Os valores de GMD e GPA variaram durante o período de avaliação (Tabela 3). Esse resultado pode ser explicado pelo aumento na taxa de acúmulo e massa

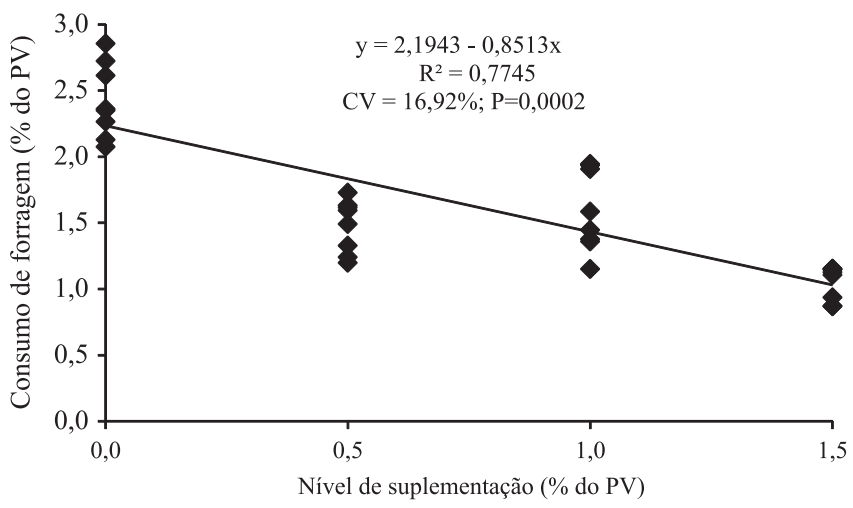

Figura 3. Consumo de forragem por cabritas em recria, suplementadas com $0,0,5,1$ e $1,5 \%$ do peso vivo (PV), em pastagem de aveia-preta.
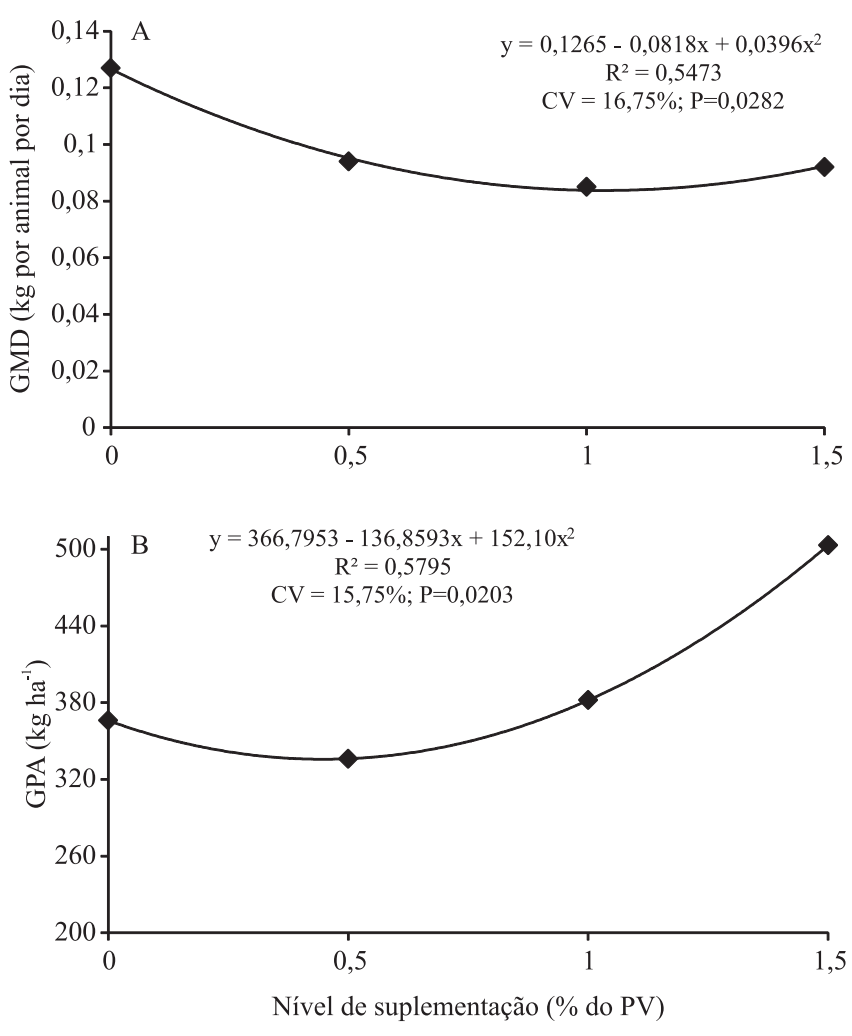

Figura 4. Médias do ganho médio diário (GMD, A) e ganho de peso por área (GPA, B) de cabritas em recria, suplementadas com $0,0,5,1$ e $1,5 \%$ do peso vivo (PV), em pastagem de aveia-preta. 
Tabela 3. Ganho médio diário e ganho de peso por área, em consequência dos períodos de avaliação de cabritas em recria, suplementadas com $0,0,5,1$ e $1,5 \%$ do peso vivo $(\mathrm{PV})$, em pastagem de aveia-preta ${ }^{(1)}$.

\begin{tabular}{lcc}
\hline Período & $\begin{array}{c}\text { Ganho médio diário } \\
(\text { kg por animal por dia })\end{array}$ & $\begin{array}{c}\text { Ganho de peso por área } \\
\left(\mathrm{kg} \mathrm{ha}^{-1}\right)\end{array}$ \\
\hline $15 / 6$ a 30/6 & $0,111 \mathrm{ab}$ & $92 \mathrm{bc}$ \\
$1 / 7$ a $21 / 7$ & $0,110 \mathrm{ab}$ & $109 \mathrm{ab}$ \\
$22 / 7$ a $10 / 8$ & $0,083 \mathrm{~b}$ & $74 \mathrm{c}$ \\
$11 / 8$ a 31/8 & $0,134 \mathrm{a}$ & $122 \mathrm{a}$ \\
\hline Média & 0,110 & 99,3 \\
\hline
\end{tabular}

${ }^{(1)}$ Médias seguidas por letras iguais não diferem pelo teste Tukey, a 5\% de probabilidade.

de forragem entre a quarta e quinta datas de avaliação, decorrentes do incremento da carga animal com os animais reguladores, a fim de manter a pastagem dentro do critério de manejo preconizado. A interação entre nível de suplementação e período de avaliação também foi significativa $(p<0,05)$, tendo sido observados incrementos de carga em todos os períodos, com o uso do suplemento. Os incrementos, no entanto, foram maiores com o avançar do experimento, em que foram observadas diferenças significativas entre os valores de beta das equações lineares, dentro de cada período. Isto pode ter ocorrido em razão do ajuste necessário da carga a cada período e da maior substituição com o avançar do peso dos animais, que aumentaram, em média, $40 \%$ o seu peso durante o período do experimento.

\section{Conclusões}

1. O fornecimento de suplemento energético para cabritas mantidas em pastagem de aveia-preta, na fase de recria, diminui o consumo de forragem, o desempenho animal individual e o tempo de pastejo, não altera o tempo de ruminação, e aumenta o tempo de ócio.

2. O ganho de peso por área aumenta a partir do fornecimento de $0,44 \%$ do PV de suplemento.

\section{Referências}

AGUINAGA, A.A.Q.; CARVALHO, P.C. de F.; ANGHUINONI, I.; SANTOS, D.T. dos; FREITAS, F.K. de; LOPES, M.T. Produção de novilhos superprecoces em pastagem de aveia e azevém submetida a diferentes alturas de manejo. Revista Brasileira de Zootecnia, v.35, p.1765-1773, 2006. DOI: 10.1590/ S1516-35982006000600026.

AHUYA, C.O.; OJANGOB, J.M.K.; MOSIC, R.O.; PEACOCK, C.P.; OKEYO, A.M. Performance of Toggenburg dairy goats in smallholder production systems of the eastern highlands of Kenya. Small Ruminant Research, v.83, p.7-13, 2009. DOI: 10.1016/j. smallrumres.2008.11.012.

ASSMANN, T.S.; ASSMANN, A.L.; ASSMANN, J.M.; SOARES, A.B.; BORTOLI, M.A. de. Produção de gado de corte e de pastagem de aveia (Avena spp.) em sistema integração lavoura pecuária em presença e ausência de trevo (Trifolium spp.) e nitrogênio. Revista Brasileira de Zootecnia, v.39, p.1387-1397, 2010. DOI: 10.1590/ S1516-35982010000700001.

BARGO, F.; MULLER, L.D.; KOLVER, E.S.; DELAHOY, J.E. Invited review: production and digestion of supplemented dairy cows on pasture. Journal of Dairy Science, v.86, p.1-42, 2003. DOI: $10.3168 /$ jds.S0022-0302(03)73581-4.

CLARK, D.A.; WOODWARD, S.L. Supplementation of dairy cows, beef cattle and sheep grazing pasture. In: RATTRAY, P.V.; BROOKES, I.M.; NICOL, A.M. (Ed.). Pasture and supplements for grazing animals. Hamilton: New Zealand Society of Animal Production, 2007. p.117-132.

COSGROVE, G.P.; EDWARDS, G.R. Control of grazing intake. In: RATTRAY, P.V.; BROOKES, I.M.; NICOL, A.M. Pastures and supplements for grazing animals. Hamilton: New Zealand Society of Animal Production, 2007. p.61-80.

FRESCURA, R.B.M.; PIRES, C.C.; ROCHA, M.G. da; SILVA, J.H.S. da; MÜLLER, L. Sistemas de alimentação na produção de cordeiros para abate aos $28 \mathrm{~kg}$. Revista Brasileira de Zootecnia, v.34, p.1266-1277, 2005. DOI: 10.1590/ S1516-35982005000400023

GIBB, M.J.; HUCKLE, C.A.; NUTHALL, R. Effects of level of concentrate supplementation on grazing behaviour and performance by lactating dairy cows grazing continuously stocked grass swards. Journal of Animal Science, v.74, p.319-335, 2002.

GONÇALVES, E.N.; CARVALHO, P.C. de F.; KUNRATH, T.R.; CARASSAI, I.J.; BREMM, C.; FISCHER, V. Relações planta-animal em ambiente pastoril heterogêneo: processo de ingestão de forragem. Revista Brasileira de Zootecnia, v.38, p.1655-1662, 2009. DOI: 10.1590/S1516-35982009000900003.

HODGSON, J. Grazing management: science into practice. New York: Longman Scientific and Technical, 1990. 203p.

JAMIESON, W.S.; HODGSON, J. The effect of daily herbage allowance and sward characteristics upon the ingestive behaviour and herbage intake of calves under strip-grazing management. Grass and Forage Science, v.34, p.261-271, 1979. DOI: 10.1111/ j.1365-2494.1979.tb01478.x.

JOCHIMS, F.; PIRES, C.C.; GRIEBLER, L.; BOLZAN, A.M.S.; DIAS, F.D.; GALVANI, D.B. Comportamento ingestivo e consumo de forragem por cordeiras em pastagem de milheto recebendo ou não suplemento. Revista Brasileira de Zootecnia, v.39, p.572-581, 2010. DOI: $10.1590 / \mathrm{S} 1516-35982010000300017$.

KAPS, A.M.; LAMBERSON, W.R. Biostatistics for animal science. London: CABI Publishing, 2004. 445p. DOI: 10.1079/9780851998206.0000.

MAACK, R. Geografia física do Estado do Paraná. Curitiba: Banco de Desenvolvimento do Paraná, 1968. 350p.

MOTT, G.E.; LUCAS, H.L. The design, conduct and interpretation of grazing trials on cultivated and improved pastures. In: 
International Grassland Congress, 6., 1952, State College. Proceedings. State College: Pennsylvania State College, 1952. p.1380-1395.

NATIONAL RESEARCH COUNCIL. Nutrient requirements of small ruminants: sheep, goats, cervids and new world camelids. Washington: NRC, 2007.

OLIVEIRA, E.L. de (Coord.). Sugestão de adubação e calagem para culturas de interesse econômico no Estado do Paraná. Londrina: IAPAR, 2003. 30p.

PELLEGRINI, L.G. de; MONTEIRO, A.L.G.; NEUMANN, M.; MORAES, A. de; BONA FILHO, A.; MOLENTO, M.B.; PELLEGRIN, A.C.R.S. de. Produção de cordeiros em pastejo contínuo de azevém anual submetido à adubação nitrogenada. Ciência Rural, v.40, p.1399-1404, 2010. DOI: 10.1590/ S0103-84782010005000095.

SANTOS, H.G. dos; JACOMINE, P.K.T.; ANJOS, L.H.C. dos; OLIVEIRA, V.A. de; OLIVEIRA, J.B. de; COELHO, M.R.;
LUMBRERAS, J.F.; CUNHA, T.J.F. (Ed.). Sistema brasileiro de classificação de solos. 2.ed. Rio de Janeiro: Embrapa Solos, 2006. $306 \mathrm{p}$.

SIMPLÍCIO, A.A.; WANDER, A.E.; LEITE, E.R.; LOPES, E.A. A caprino-ovinocultura de corte como alternativa para a geração de emprego e renda. Sobral: Embrapa Caprinos, 2004. 44p. (Embrapa Caprinos. Documentos, 48).

VAN SOEST, P.J. Nutritional ecology of the ruminant. 2.ed. Ithaca: Cornell University, 1994. 476p.

VAN WYK, J.A.; CABARET, J.; MICHAEL, L.M. Morphological identification of nematode larvae of small ruminants and cattle simplified. Veterinary Parasitology, v.119, p.277-306, 2004. DOI: 10.1016/j.vetpar.2003.11.012.

WILLIAMS, C.H.; DAVID, D.J.; LISMAA, O. The determination of chromic oxide in faeces samples by atomic absorption spectrophotometry. The Journal of Agricultural Science, v.59, p.381-385, 1962. DOI: 10.1017/S002185960001546X.

Recebido em 25 de junho de 2012 e aprovado em 30 de janeiro de 2013 